\title{
Tricuspid three-dimensional ring versus fashioned flexible band annuloplasty in management of functional tricuspid valve regurge: comparative long term study
}

\author{
Abdallah Nosair ${ }^{1^{*}}$ (D) Mohamed Elkahely ${ }^{2}$ (D) Sherif Nasr $^{3}$ and Hesham Alkady ${ }^{1}$
}

\begin{abstract}
Background: Functional tricuspid valve regurgitation due to left sided valve lesions remains a common finding. Nowadays, different types of three-dimensional rings and flexible bands are considered to be the gold standard techniques for repair of such functional regurgitation. Our study aimed for long-term comparison of the durability and effectiveness of those techniques.

Results: The data of 170 adult patients with moderate or more functional tricuspid regurgitation secondary to mitral stenosis or regurgitation receiving tricuspid valve repair using either rigid 3D rings (contour 3D or MC3 ring) or prosthetic fashioned bands (Dacron or PTFE) and mitral valve surgery between March 2013 and September 2018 were collected and analysed. Patients were classified in two matched groups: ring group (group A) consisting of 90 cases and band group (group B) consisting of 80 cases. follow-up period ranged from 55.2 to 78 months (mean $67.2 \pm 10.8$ ), during this period New York heart association for dyspnea functional class evaluation and full echocardiographic assessment were done and was scheduled as following: before hospital discharge, after 6 months of surgery and finally, every 2 years. In-hospital mortality was $1(1.1 \%)$ and $2(2.5 \%)$ with $p$ value 0.49 after ring or band annuloplasty, respectively. No significant differences in both groups regarding hospital mortality and morbidities. There was statistically significant decrease in NYHA class, degree of TR, and PASP within the 2 groups postoperatively with $p$ value of $0.03,0.04$, and 0.033 , respectively, with no statistically significant difference between both groups ( $p$ value $>0.05$ ). There was statistically significant difference in the freedom from recurrent TR and need for reoperation during the follow-up period between both groups with lower recurrence and reoperation rates in group $A$, ( $p$ value 0.03 and 0.001 , respectively).

Conclusion: Tricuspid valve repair with different annuloplasty rigid three dimensional rings or fashioned flexible bands for functional tricuspid regurgitation offers good long-term outcome. Yet, the rigid rings maintain their benefits on the rate of recurrent TR and the need for reoperation.
\end{abstract}

Keywords: Functional tricuspid regurgitation, Band annuloplasty, Tricuspid 3D ring

\footnotetext{
* Correspondence: abdallah_nosair@live.com

1 Department of Cardiothoracic Surgery, Faculty of Medicine, Cairo University,

Cairo, Egypt

Full list of author information is available at the end of the article
}

\section{Springer Open}

(c) The Author(s). 2020 Open Access This article is licensed under a Creative Commons Attribution 4.0 International License, which permits use, sharing, adaptation, distribution and reproduction in any medium or format, as long as you give appropriate credit to the original author(s) and the source, provide a link to the Creative Commons licence, and indicate if changes were made. The images or other third party material in this article are included in the article's Creative Commons licence, unless indicated otherwise in a credit line to the material. If material is not included in the article's Creative Commons licence and your intended use is not permitted by statutory regulation or exceeds the permitted use, you will need to obtain permission directly from the copyright holder. To view a copy of this licence, visit http://creativecommons.org/licenses/by/4.0/. 


\section{Backgrounds}

Functional tricuspid regurgitation (FTR) remains a common finding in patients with left-sided valvular heart diseases especially mitral valve regurgitation or stenosis. It is mainly caused by dilatation and flattening of the tricuspid valve (TV) annulus as a result of right ventricular (RV) enlargement and is inevitably affected by the RV function [1]. Multiple studies support the better outcome of using rigid ring annuloplasty over suture repair for treating FTR in concern with the durability and freedom from residual regurgitation. These studies refer the superiority of rigid ring annloplasty to the threedimensional configuration achieved by such rings which matches the normal tricuspid annulus and, at the same time, to the rigid support of the annulus [2-6]. On the other hand, other studies support the use of flexible prosthetic bands like Dacron or polytetrafluroethilin (PTFE), especially over suture techniques, due to their easy applicability and availability with good postoperative results $[7,8]$. Therefore, suture annyloplasty became nowadays less convenient for FTR repair since both flexible bands and rigid rings appeared to offer good midterm outcomes in recent meta-analysis studies $[9,10]$. However, the ideal annuloplasty method for repairing FTR is still debatable between the three-dimensional (3D) rigid rings versus flexible prosthetic bands regarding the long-term outcome. In this retrospective comparative study, we share our experience with long-term outcome of using 3D rigid rings and flexible fashioned bands in FTR.

\section{Methods}

\section{Study method}

Between March 2013 and September 2018, a total of 367 patients with moderate or more FTR secondary to mitral stenosis or regurgitation underwent tricuspid valve repair and mitral valve surgery at Cairo University hospitals. Of these, 90 cases received tricuspid valve repair with rigid $3 \mathrm{D}$ rings (contour $3 \mathrm{D}$ or $\mathrm{MC} 3$ ring) while the rest (277 cases) received tricuspid valve repair with prosthetic fashioned bands (Dacron or PTFE). The data of the patients receiving tricuspid valve repair with rigid rings were collected and reviewed (group A). Another group of 80 cases receiving tricuspid valve repair with bands were matched to group A using propensity scores according to preoperative patient characteristics (group B). Cases with organic tricuspid regurgitations, recurrent tricuspid valve disease (TVD), endocarditis affecting the TV, associated tricuspid stenosis, congenital TR, associated aortic or pulmonary valve affection, and concomitant ischemic heart disease were not included in our study. This study was approved by our ethical committee. An informed consent was obtained from all patients for the planned operations and due to its retrospective nature the consent for enrolment of patient data in the study was waived. The indication for surgery for the tricuspid valve in our study was based on the American Heart Association (AHA) guidelines; when TR was severe or if moderate but with tricuspid annular dilatation (> $40 \mathrm{~mm}$ ) or pulmonary artery systolic pressure (PASP) above 50 [11]. The TR severity was assessed by the $M$ mode, two dimension and Doppler echocardiography. Moderate TR (grade 2+) was defined by a width of vena contracta of 4-7 $\mathrm{mm}$ and a jet area of $5-10 \mathrm{~cm}^{2}$. Severe TR (grade $3+$ and $4+$ ) was defined by a width of vena contracta of 7 > $\mathrm{mm}$ and a jet area of $10>\mathrm{cm}^{2}$ with systolic flow reversal in hepatic veins. Data were categorized into; preoperative, operative, postoperative, and follow-up which ranged from 4.6 to 6.5 years (mean $5.6 \pm 0.9$ ). In-hospital mortality was defined by deaths within 30 days of the operation. Recurrent TR was defined by postoperative moderate or more TR (grade 2+ or more).

\section{Data collection:}

Full data was recorded and analyzed as following:

Preoperative data: age, sex, New York Heart Association (NYHA) class for dyspnea, transthoracic echo (TTE) findings including: ejection fraction (EF), left ventricle end diastolic dimensions (LVEDD), left ventricle end systolic dimensions (LVESD), systolic pulmonary pressure (SPAP) in $\mathrm{mmHg}$. We will consider it as mild, moderate, and severe pulmonary hypertension, respectively, with the values of $30-45 \mathrm{mmHg}, 45-70 \mathrm{mmHg}$, and $>70 \mathrm{mmHg}$.TR Jet area $(\mathrm{cm} 2)$, vena contracta width which measures the narrowest distance of the tricuspid jet in $\mathrm{mm}$, tricuspid annular plane systolic excursion (TAPSE), which measures the longitudinal systolic motion of the free edge of the tricuspid valve annulus, tricuspid annulus (TA) diameter, and mid RV diameter in short axis

\section{Operative data}

Full records of cardiopulmonary bypass time, cross clamp time, intra-operative findings, type of ring or band in each group, and type of mitral valve intervention.

\section{Postoperative data}

Duration of mechanical ventilation, need for pacemaker, intensive care unit (ICU) stay, hospital stay, morbidities, mortality, and follow-up echo data as scheduled by TTE preoperatively as a baseline, then, intra-operative transoesophageal echocardiography (TEE) for correlation with the preoperative echo, postoperative TTE before hospital discharge, then, in outpatient clinic after 6 months of surgery and finally, every 2-year of follow-up 
for all patients in both groups with comparison with the preoperative NYHA,TR grade, PASP, and EF. Follow-up period ranged from 55.2 to 78 months (mean $67.2 \pm$ 10.8).

\section{Operative procedure}

Surgery was done in all cases through full median sternotomy and cardiopulmonary bypass (CPB) was achieved with routine bicaval cannulation. Myocardial protection was carried out with multi-dose cold blood cardioplegia every 30-40 min delivered in an ante-grade mode with systemic cooling to $32{ }^{\circ} \mathrm{C}$. After aortic crossclamping the concomitant mitral valve surgery, whether repair or replacement, was done first through left atriotomy. Tricuspid valve repair was then performed through right atriotomy during the rewarming period on flaccid heart with either band (Dacron or Gortex) or using rigid 3D tricuspid rings (Contour 3D (Medtronic, Minneapolis, $\mathrm{MN}$ ) ring or MC3) which were fixed to the annulus with interrupted non-pledgetted 2/0 non-absorbable (Ethibond) sutures avoiding the area of the AV node. The choice of the type of tricuspid repair was carried out according to the surgeon's preference. Sizing for rigid rings by different sizers took place according to the base of the septal leaflet (or one size smaller than the anterior tricuspid leaflet surface area). For band annuloplasty, bands of Dacron or Gortex were fashioned in a width of 3-4 $\mathrm{mm}$ and a length of 5 to $7 \mathrm{~cm}$ depending on the operative assessment of the surgeon. Finally, testing of the repair was done by saline injection into the tricuspid valve while closing the pulmonary valve before the right atrium closure (Fig. 1).

\section{Statistical analysis}

A propensity score matching (PSM) analysis to create comparable risk groups for comparing the outcome of using the two different techniques on degree of postoperative tricuspid regurge and freedom from reoperation with respect to covariates as demographics and preoperative characteristics. In PSM standardized difference

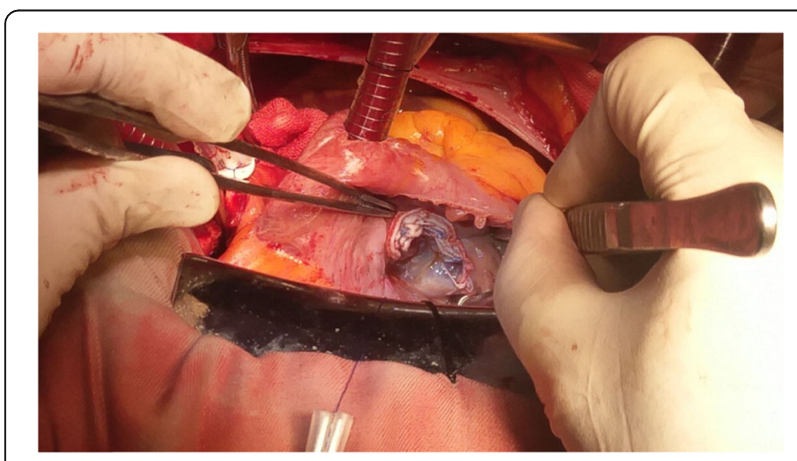

Fig. 1 tricuspid fashioned Dacron band after saline test were calculated to compare features before and after matching with imbalance being defined as an absolute value greater than 0.10 (small effect size). Matching was performed using the nearest neighbor algorithm with a calliper distance of 0.0001 . All preoperative variables > 90\% missing data were excluded from analysis. Data were reviewed and coded to facilitate data manipulation and double entered into Microsoft Access and data analysis was performed using Statistical Package of Social Science (SPSS) software version 25 in Windows 7 . Quantitative data were summarized using mean \pm standard deviation while categorical data were presented as frequency (count) and relative frequency (percentage). For two independent groups of quantitative parametric data non-paired Student's $t$ test was used while for qualitative data chi-squared test was used. Two-way ANOVA test was implied for repeated measures. A $p$ value $<0.05$ was considered the cut-off value for significance.

\section{Results}

Early results

Preoperative patient characteristics are summarized in Table 1 including epidemiological, clinical, and echocardiological data. There was no statistical significant difference between both groups, which indicates proper

Table 1 Preoperative data in both study groups

\begin{tabular}{|c|c|c|c|c|}
\hline \multicolumn{2}{|l|}{ Variables } & $\begin{array}{l}\text { Ring group } \\
(n=90)\end{array}$ & $\begin{array}{l}\text { Band group } \\
(n=80)\end{array}$ & $p$ value \\
\hline \multicolumn{5}{|l|}{ Sex } \\
\hline \multicolumn{2}{|l|}{ Male } & $33(36.7 \%)$ & $28(35 \%)$ & 0.8 \\
\hline \multicolumn{2}{|l|}{ Female } & $57(63.3 \%)$ & $52(65 \%)$ & \\
\hline \multicolumn{2}{|l|}{ Age (years) } & $39.7 \pm 6.5$ & $37.9 \pm 7.5$ & 0.08 \\
\hline \multirow[t]{3}{*}{ TR grads } & $\|$ & $36(40 \%)$ & $24(30 \%)$ & 0.15 \\
\hline & III & $18(20 \%)$ & $12(15 \%)$ & \\
\hline & IV & $36(40 \%)$ & $44(55 \%)$ & \\
\hline \multicolumn{2}{|c|}{$\begin{array}{l}\text { Mitral valve lesions } \\
\text { Stenosis } \\
\text { Regurgitation } \\
\text { Stenosis and regurgitation }\end{array}$} & $\begin{array}{l}74(82 \%) \\
4(5 \%) \\
12(13 \%)\end{array}$ & $\begin{array}{l}65(81 \%) \\
2(2.5 \%) \\
13(16.5 \%)\end{array}$ & 0.75 \\
\hline \multicolumn{2}{|l|}{ NYHA class } & $2.9 \pm 0.85$ & $3.1 \pm 0.92$ & 0.14 \\
\hline \multicolumn{2}{|l|}{ LVEF \% } & $53.3 \pm 16.8$ & $55.2 \pm 18.9$ & 0.49 \\
\hline \multicolumn{2}{|l|}{ LVSD (cm) } & $3.7 \pm 0.0 .98$ & $3.92 \pm 0.53$ & 0.07 \\
\hline \multicolumn{2}{|c|}{ LVEDD (cm) } & $6.04 \pm 0.98$ & $5.87 \pm 0.56$ & 0.16 \\
\hline \multicolumn{2}{|l|}{ TAPSI (cm) } & $1.8 \pm 0.43$ & $1.9 \pm 0.3$ & 0.08 \\
\hline \multicolumn{2}{|c|}{ RV short axis (cm) } & $2.93 \pm 0.37$ & $2.99 \pm 0.4$ & 0.13 \\
\hline \multicolumn{2}{|c|}{ TA diameter (cm) } & $4.8 \pm 0.4$ & $4.7 \pm 0.5$ & 0.15 \\
\hline \multicolumn{2}{|c|}{ PASP (mmHg) } & $63.52 \pm 9.95$ & $61.23 \pm 10.25$ & 0.14 \\
\hline
\end{tabular}

TR tricuspid regurgitation, NYHA New York Heart Association, LVEF left ventricular ejection fraction, $L V E D D$ left ventricle end diastolic dimensions, LVESD left ventricle end systolic diameter, TAPSE tricuspid annular plane systolic excursion, $R V$ right ventricular, $T A$ tricuspid annulus, SPAP systolic pulmonary artery pressure 
matching between the two study groups. The pathology of the mitral valve affection was rheumatic in origin in all cases of the study. The sizes of the rigid rings (MC3 in 20 cases and Contour 3D in 70 cases) used in group A ranged from 28 to $34 \mathrm{~cm}$ with a mean value of 30.5 $\mathrm{cm}$. On the other hand, fixed lengths of 5 to $7 \mathrm{~cm}$ of flexible fashioned bands (Dacron in 70 cases and Gortex in 10 cases) were used in group B. There was statistical significant difference of bypass time and cross clamp time being shorter in group B. Other operative and postoperative parameters are shown in Table 2 with no statistically significant differences between both groups. One case $(1.1 \%)$ died in group A due to multi-organ failure while two cases $(2.5 \%)$ died in group B from refractory low cardiac output in one patient and respiratory failure due to pneumonia and prolonged ventilation in the other case with no significant difference. On comparison between the preoperative and postoperative values for NYHA class, degree of TR, and PASP, there was statistically significant decrease in the immediate postoperative period within the 2 groups with a $p$ value of $0.03,0.04$, and 0.033 , respectively. However, there was no statistically significant difference between both groups ( $p$ value $=0.065)$.

\section{Late results and follow-up}

Our complete long-term follow-up was achieved in 134 (78.82\%) cases due to mortalities and patients noncompliance (8.8\%). Follow-up period ranged from 55.2 to 78 months (mean $67.2 \pm 10.8$ ). Late deaths occurred in $18(10.58 \%)$ of cases. Ten cases in group A as well as in 8 case in group B due to infective endocarditis in 4 cases, stuck mitral valves in 3 cases, cerebrovascular events in 3 cases, renal failure in 2 cases, malignancy in 2 cases, and 4 unknown causes with no statistically significant difference (Fig. 2).

There was no statistically significant difference in the mean NYHA class during the follow-up period between both groups (0.91 in group A and 0.92 in group B) with a $p$ value of 0.09 (Fig. 3). Also, PASP and EF\% showed no statistical difference in the same follow-up periods between both groups. However, there was a statistically significant difference in the mean degree of TR improvement at the same follow-up period in favor of group A ( 1 in group A and 1.5 in group B) with a $p$ value of 0.03 . The degree of improvement and severity of TR in the follow-up period is shown in Fig. 4.

In addition, 7 cases $(8.75 \%)$ out of the 80 patients in group B and $4(4.4 \%)$ out of the 90 patients in group A had recurrent TR during follow-up period. Four patients from the 7 cases with recurrent TR in the band group needed reoperation with replacement of the tricuspid valve due to recurrent right sided heart failure despite maximal medical treatment. On the other side, the four patient with recurrent TR in ring group continued their follow-up period without reoperation. There was statistically significant difference in the freedom from recurrent $\mathrm{TR}$ and need for reoperation during the follow up period

Table 2 Operative and outcome data in both study groups

\begin{tabular}{|c|c|c|c|}
\hline Variables & $\begin{array}{l}\text { Ring group } \\
(n=90)\end{array}$ & $\begin{array}{l}\text { Band group } \\
(n=80)\end{array}$ & $p$ value \\
\hline Bypass time (min) & $116 \pm 25.41$ & $105.6 \pm 20.33$ & $<0.001 *$ \\
\hline Cross clamp time (min) & $91 \pm 28.6$ & $76.7 \pm 30.2$ & $<0.001 *$ \\
\hline Concomitant mitral valve surgery Repair & $6(6.7 \%)$ & $4(5 \%)$ & 0.64 \\
\hline Replacement & $84(93.3 \%)$ & $76(95 \%)$ & \\
\hline Types of ring or band & $\begin{array}{l}\text { MC3 20: (22.2\%) } \\
\text { Contour 3D: } 70 \text { (77.8\%) }\end{array}$ & $\begin{array}{l}\text { Dacron: } 70(87.5 \%) \\
\text { Gortex: } 10(12.5 \%)\end{array}$ & \\
\hline Postoperative mechanical ventilation (h) & $8.1 \pm 1.9$ & $7.7 \pm 1$ & 0.08 \\
\hline ICU stay (days) & $2.9 \pm 0.76$ & $2.6 \pm 1.3$ & 0.07 \\
\hline Hospital stay (days) & $7.4 \pm 1.2$ & $7.8 \pm 1.5$ & 0.06 \\
\hline $\begin{array}{l}\text { Postoperative complications } \\
\text { Reoperation for bleeding }\end{array}$ & $5(5.6 \%)$ & $3(3.8 \%)$ & 0.9 \\
\hline Renal failure & $2(2.2 \%)$ & $2(2.5 \%)$ & \\
\hline Cerebrovascular stroke & $1(1.1 \%)$ & $1(1.3 \%)$ & \\
\hline New pacemaker insertion & $1(1.1 \%)$ & $0(0 \%)$ & \\
\hline Tracheostomy & $0(0 \%)$ & $1(1.25 \%)$ & \\
\hline Pneumonia & $0(0 \%)$ & $2(2.5 \%)$ & \\
\hline In-hospital mortality & $1(1.1 \%)$ & $2(2.5 \%)$ & 0.49 \\
\hline Reoperation for recurrence & $0(0 \%)$ & $4(5 \%)$ & $0.001^{*}$ \\
\hline
\end{tabular}




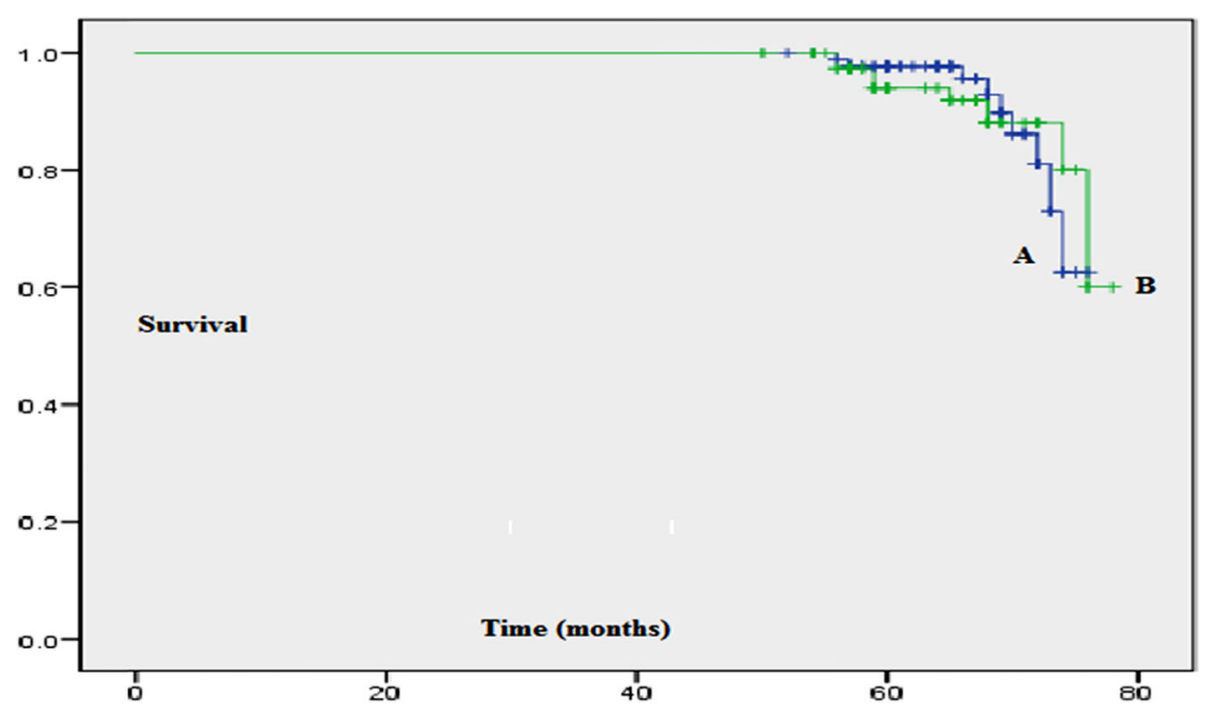

Fig. 2 Kaplan-Meier curve for survival

between both groups with lower recurrence and reoperation rates in group A with a $p$ value of 0.03 and 0.001 respectively (Fig. 5).

\section{Discussion}

Secondary FTR is very common at the time of left sided valve surgery due to progressive annular dilatation mainly leading to lack of proper tricuspid leaflets coaptation and regurge. Furthermore, the changes that occurs in valve geometry and the more planer the tricuspid annulus that become with prolonged dilatation.

Current data suggest that the dilatation that occurs in cases of FTR especially with left-sided valve lesions is an on-going process that continues to progress unless surgical annuloplasty is done at the time of left-sided valve surgery to prevent future progression of the disease [12]. Without intervention, persistent TR is currently associated with poor outcome even if not sever and therefore, the recommendations for repairing the FTR nowadays changed to lesser threshold for regurgitation [13].

The main difference between both rigid 3D rings and flexible fashioned bands is that rigid rings restore the saddle, non-planner, and tricuspid annulus which have been proven by the studies using 3D echocardiography to improve annular symmetrical contractions during the cardiac cycle. In addition, rigid rings seem to give more long-term stability of the tricuspid annulus [14]. On the other hand, flexible bands maintain the physiological motion of the tricuspid annulus during cardiac contractions which is now well-recognized by many researches but its clinical importance and role are not yet fully investigated [15].

In our study, the mean size of used rigid rings was 30.5 (range 28-34). We simply used one size smaller of the 3D ring (contour 3D or MC3) since some studies showed that the exact annular size is relatively smaller when the heart is beating than when arrested. Also,

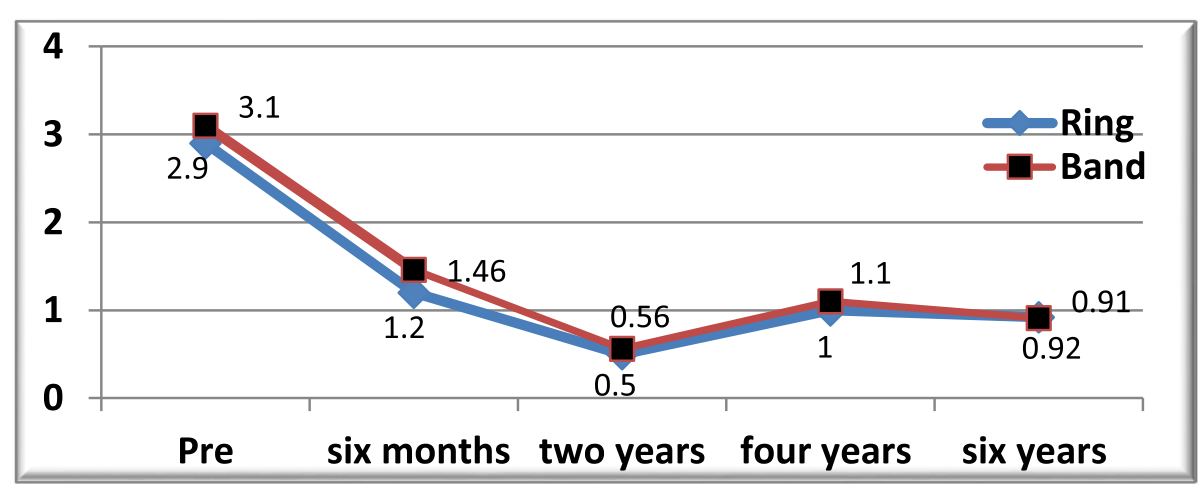

Fig. 3 Postoperative NYHA class follows-up in study groups 


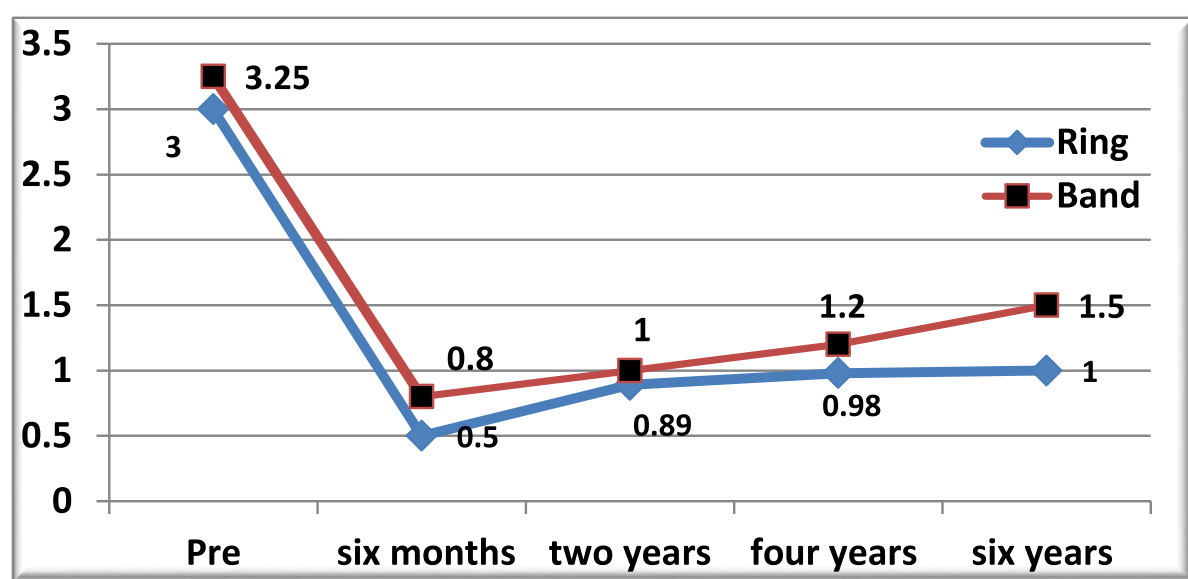

Fig. 4 Postoperative TR pattern during the follow-up period in both study groups

other studies recommended routine downsizing in all cases whether performing the tricuspid repair on beating or arrested heart with comparable results $[3,16]$. However, multiple studies failed to identify a concrete relation between the ring size, as a risk factor, and recurrent TR with no much benefits of aggressive downsizing $[17,18]$.

On the other hand, we fashioned the bands to a width of $3 \mathrm{~mm}$ and a length of 5 to $7 \mathrm{~cm}$ to plicate the anterior and posterior annulus depending upon the intraoperative measurement of the tricuspid annulus and the degree of TR. Although the fact that there are no solid guidelines for this measurement, but this length has been obtained in previous studies from the average circumferences of most used ring sizers. In addition, it has been shown in previous studies that the tricuspid annulus measured by preoperative echocardiography from the mid-anterior to the mid-septal leaflet in the enddiastole using the apical four chamber view differs from the transvers annulus measured surgically from the antero-septal commissure to the antero-posterior commissure. For example, an annulus estimated by preoperative echocardiography to be $4 \mathrm{~cm}$ would be measured surgically $7 \mathrm{~cm}[19]$.

In the band group, we used Dacron or Gortex assuming that both has nearly equal flexibility with fashioning the band $3 \mathrm{~mm}$ width and from 5 to $7 \mathrm{~cm}$ length depending upon the intraoperative measurement of the tricuspid annulus and to what degree the TR present and the needs for the proper downsizing with no solid guidelines for measurement but, we took this measurement previously from average circumferences of most used ring sizers.

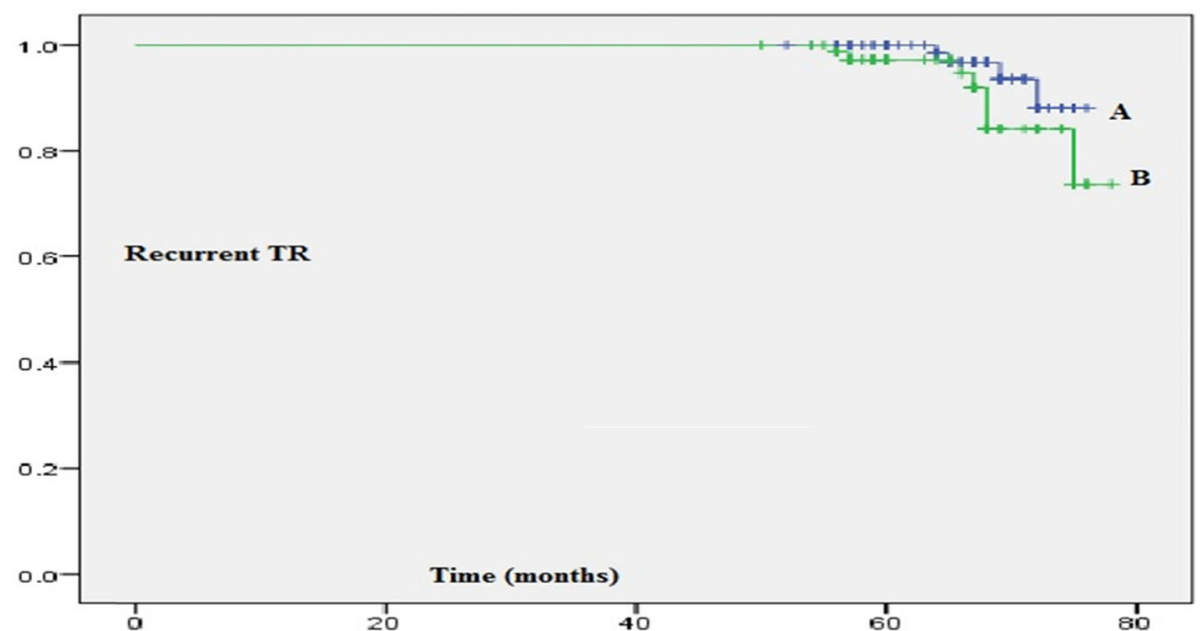

Fig. 5 Freedom from recurrent TR at different follows up periods in the study groups 
In our series, we have succeeded effectively to reduce the tricuspid annulus size by either the rigid rings or fashioned flexible bands with no statistically significant difference in both modalities in the aspect of improving the TR degree, PASP and NYHA class in the early postoperative period. However, rigid $3 \mathrm{D}$ rings significantly maintained long-term effects on the repair with less reintervention and recurrent TR during our follow-up. This finding agrees with previous multiple studies and meta-analysis comparing rigid rings with flexible band devices, not fashioned (custom made) bands, as we tried. We use these intra-operatively fashioned bands for easy accessibility and applicability with similar concepts [9, 10, 20-22]. Moreover, some studies used native pericardium fashioned into similar bands as it is widely available for all patients with encouraging results [8, 23].

Nevertheless, most of the studies addressing the risk factors for recurrent TR after surgical repair of FTR reported LV dysfunction, high preoperative PASP and the presence of tricuspid valve tethering $[24,25]$ these studies could not identify the type of annuloplasty as a risk factor for recurrent TR which implies the importance of multi-centric prospective studies with long term results. We could not include TV tethering in our preoperative echo parameters, and we did not study the risk factors for recurrence as PASP, also, mean LVEF was in normal rang in our preoperative data and maintained in the long-term follow-up with no significant changes to be a risk factor.

\section{Study limitations}

Our study has several limitations. The retrospective nature of the study and the sample size was relatively small. There is procedural difference between fashioned bands which cover the anterior and posterior annulus only and rigid rings which cover in addition part of septal annulus. There were no standard guidelines for sizing the fashioned tricuspid bands. The risk factors for recurrence have not been studied. Finally, the study did not compare different annuloplasty material used in bands or different manufactured rigid rings.

\section{Conclusion}

Tricuspid valve repair with different annuloplasty rigid three-dimensional rings or fashioned flexible bands for functional tricuspid regurgitation offers good long-term outcome. Yet, the rigid rings on the long run maintain their benefits on decreasing the rate of recurrent TR and the need for reoperation.

\section{Abbreviations}

AHA: American heart association; CPB: Cardiopulmonary bypass; EF: Ejection fraction; FTR: Functional tricuspid regurgitation; ICU: Intensive care unit; LVEDD: Left ventricle end diastolic dimensions; LVESD: Left ventricle end systolic dimensions; NYHA: New York Heart Association;
PTFE: Polytetrafluroethilin; RV: Right ventricular; SPAP: Systolic pulmonary pressure; SPSS: Statistical Package of Social Science; TR: Tricuspid regurgitation; TVD: Tricuspid valve disease; TTE: Transthoracic echo; TAPSE: Tricuspid annular plane systolic excursion; TA: Tricuspid annulus; TEE: Trans-oesophageal echocardiography; 3D: Three dimensions

\section{Acknowledgements}

Thanks to our statistical member in this study Dr. Asma Elsary who did great effort in organizing and illustrating the data to be clear in our results.

\section{Authors' contributions}

All authors participated in getting the conception, data collection, analysis, and manuscripts writing. ME was a major contributor in analysis and interpreted the patient data regarding the comparative parameters. AN was a major contributor in writing the manuscript. SN was major contributor in revising and editing the manuscript. HE was major contributor in revising and editing the manuscript. All authors read and approved the final manuscript.

Funding

Not applicable

Availability of data and materials

Available by the corresponding author upon request

Ethics approval and consent to participate

Not applicable

\section{Consent for publication}

Duo to the retrospective nature patients, consent for publication was waved.

\section{Competing interests}

The authors declare that they have no competing interests.

\section{Author details}

${ }^{1}$ Department of Cardiothoracic Surgery, Faculty of Medicine, Cairo University, Cairo, Egypt. ${ }^{2}$ Department of Cardiothoracic Surgery, Faculty of Medicine for Girls, Al-Azhar University, Cairo, Egypt. ${ }^{3}$ Department of Cardiothoracic Surgery, Faculty of Medicine, Fayoum University, Fayoum, Egypt.

Received: 18 January 2020 Accepted: 22 April 2020

Published online: 11 May 2020

\section{References}

1. Rashwan O, Nosair A et al (2017) Mid-term results of three dimentional annuloplasty ring repair in treating functional tricuspid valve regurgitation. Journal of the Egyptian Society of Cardiothorac Surg. 25:316-322

2. Naqshband MS, Abid AR, Akhtar RP, Waheed A, Khan JS (2010) Functional tricuspid regurgitation in rheumatic heart disease: surgical options. Ann Thorac Cardiovasc Surg 16:417-425

3. Ghoreishi M, Brown JM, Stauffer CE, Young CA, Byron MJ, Griffith BP et al (2011) Undersized tricuspid annuloplasty rings optimally treat functional tricuspid regurgitation. Ann Thorac Surg 92:89-96

4. Basel H, Aydin U, Kutlu H, Dostbil A, Karadag M, Odabasi D et al (2010) Outcomes of De Vega versus biodegradable ring annuloplasty in the surgical treatment of tricuspid regurgitation (mid-term results). Heart Surg Forum 13:233-237

5. Navia $J$, Brozzi NA, Klein AL et al (2012) Moderate tricuspid regurgitation with left-sided degenerative heart valve disease: to repair or not to repair? Ann Thorac Surg 93:59-67 discussion 68-9

6. Ren WJ, Zhang BG et al (2015) Outcomes of tricuspid annuloplasty with and without prosthetic rings: a retrospective follow-up study. Journal of Cardiothorac Surg. 10:81

7. Abdelfattah I, Omar A (2014) Early outcome of tricuspid repair for functional tricuspid regurgitation associated with rheumatic mitral valve disease modified flexible band annuloplasty vs. suture annuloplasty. Journal of the Egyptian Society of Cardio-Thoracic Surgery 22:13-18

8. Chang BC, Song SW, Lee S, Yoo KJ, Kang MS, Chung N (2008) Eight-year outcomes of tricuspid annuloplasty using autologous pericardial strip for functional tricuspid regurgitation. Ann Thorac Surg 86:1495-1493 
9. Zhu TY, Wang JG, Meng $X$ (2013) Is a rigid tricuspid annuloplasty ring superior to a flexible band when correcting secondary tricuspid regurgitation? Interactive CardioVascular and Thoracic Surgery. 17:10091014

10. Wang N, Phan S, Tian DH et al (2017) Flexible band versus rigid ring annuloplasty for tricuspid regurgitation: a systematic review and metaanalysis. Ann Cardiothorac Surg 6:194-203

11. Nishimura Rick A, Otto Catherine M, Bonow Robert O et al (2014) AHA/ACC guideline for the management of patients with valvular heart disease: a report of the American college of cardiology/American heart association task force on practice guidelines. Circulation 129

12. Dreyfus GD, Corbi PJ, Chan KM, Bahrami T (2005) Secondary tricuspid regurgitation or dilatation: which should be the criteria for surgical repair? Ann Thorac Surg 79:127-132

13. Seo HS, Ha JW, Moon JY et al (2008) Right ventricular remodeling and dysfunction with subsequent annular dilatation and tethering as a mechanism of isolated tricuspid regurgitation. Circ J 72:1645-1649

14. Jouan J, Pagel MR, Hiro ME et al (2007) Further information from a sonometric study of the normal tricuspid valve annulus in sheep: geometric changes during the cardiac cycle. J Heart Valve Dis 16:511-518

15. Ton-Nu TT, Levine RA, Handschumacher MD et al (2006) Geometric determinants of functional tricuspid regurgitation: insights from 3dimensional echocardiography. Circulation. 114:143-149

16. Filsoufi F, Salzerg SP, Coutu M, Adams DH (2006) A three-dimensional ring annuloplasty for the treatment of tricuspid regurgitation. Ann Thorac Surg 81:2273-2278

17. McCarthy PM, Bhudia SK, Rajeswaran J et al (2004) Tricuspid valve repair: Durability and risk factors for failure. J Thorac Cardiovasc Surg 127:674-685

18. Izutani H, Nakamura T, Kawachi K (2010) Flexible band versus rigid ring annuloplasty for functional tricuspid Regurgitation. Heart International 5:13

19. Gatti G, Dell'Angela L, Morosin M et al (2016) Flexible band versus rigid ring annuloplasty for functional tricuspid regurgitation: two different patterns of right heart reverse remodeling. Interactive Cardiovascular and Thoracic Surgery 23:79-89

20. Guenther T, Mazzitelli D, Noebauer C et al (2013) Tricuspid valve repair: is ring annuloplasty superior? Eur J Cardiothorac Surg 43:58-65

21. Gatti G, Dell'Angela L, Morosin M et al (2016) Flexible band versus rigid ring annuloplasty for functional tricuspid regurgitation: two different patterns of right heart reverse remodeling. Interactive Cardiovascular and Thoracic Surgery. 23:79-89

22. Adas A, Elnaggar A, Balbaa Y, Elashkar A, Alkady HM (2019) Ring, band or suture in tricuspid annuloplasty for functional tricuspid regurgitation; which is better and more durable? Heart Surg Forum. 22:411-415

23. Abdou Ettish AA, Etmanb WG, Ramadan AM, Ramadan BA (2019) Flexible band made of autologous pericardium for functional tricuspid regurgitation repair. Alexandria journal of medicine 55:44-48

24. Fukuda S, Gillinov AM, McCarthy PM et al (2006) Determinants of recurrent or residual functional tricuspid regurgitation after tricuspid annuloplasty. Circulation 114:1582-1587

25. Fukuda S, Song JM, Gillinov AM et al (2005) Tricuspid valve tethering predicts residual tricuspid regurgitation after tricuspid annuloplasty. Circulation 111:975-979

\section{Publisher's Note}

Springer Nature remains neutral with regard to jurisdictional claims in published maps and institutional affiliations.

\section{Submit your manuscript to a SpringerOpen ${ }^{\circ}$ journal and benefit from:}

- Convenient online submission

- Rigorous peer review

- Open access: articles freely available online

- High visibility within the field

- Retaining the copyright to your article

Submit your next manuscript at $\boldsymbol{\nabla}$ springeropen.com 